\title{
Geological region by multi-signal method of gravity anomaly data in central area of Vietnam
}

\author{
Hong Thi Phan $1{ }^{*}$, Petrov Aleksey Vladimirovich ${ }^{2}$, Phuong Minh Do ${ }^{3}$, \\ Luu Truong Nguyen ${ }^{3}$ \\ ${ }^{1}$ Hanoi University of Mining and Geology, Hanoi, Vietnam \\ 2 University of Geology and Exploration named Sergo Ordzhonikidze, Moscow, Russia \\ ${ }^{3}$ General Department of Geology and Minerals, Hanoi, Vietnam
}

\begin{tabular}{l} 
ARTICLE INFO \\
\hline Article history: \\
Received 11 ${ }^{\text {th }}$ May 2021 \\
Accepted 16 $6^{\text {th }}$ Aug. 2021 \\
Revised $15^{\text {th }}$ Sept. 2021 \\
\hline Keywords: \\
Bughe gravitational \\
anomaly, \\
COSCAD-3D, \\
Multi-sign method, \\
Statistical probability, Two \\
dimensional filtering.
\end{tabular}

\section{ABSTRACT}

This paper presents the research results of applying the combined method of probabilistic statistical approaches, energy density spectral correlation, two-dimensional filtering in dynamic sliding windows, full horizontal gradient and heterogeneous axis tracking method to process and interpret the Bughe gravitational anomaly field in central area Vietnam. The calculation results have shown the superiority of the twodimensional filter in dynamic sliding windows compared to the filters in fixed windows in GEOSOFT software, GMT software. According to the physical characteristics of the field, the study area was divided into 13 homogeneous classes, this result is consistent with the geological-tectonic data in the area. In the north and northeast, the stabilized rock layers are characterized by homogeneous layers that extend in the northwestsoutheast direction. In the south and southwest, there is complex tectonic activity characterized by high density rock layers overlain by low density rock layers in each fault band with different directions of development. This suggests that there may be deeply buried mineral deposits of magmatic origin in central area Vietnam.

Copyright (C) 2021 Hanoi University of Mining and Geology. All rights reserved.

${ }^{*}$ Corresponding author

E - mail: phanthihong@humg.edu.vn

DOI: 10.46326/JMES.2021.62(5).04 


\title{
Tạp chí Khoa học Kỹ thuật Mỏ - Địa chất
}

Trang điên tứ: http://tapchi.humg.edu.vn

\section{Phân vùng địa chất theo thuật toán đa dấu hiệu trường dị thường trọng lực khu vực trung tâm Việt Nam}

\author{
Phan Thị Hồng1,* , Petrov Aleksey Vladimirovich ${ }^{2}$, Đỗ Minh Phương ${ }^{3}$, Nguyễn \\ Trường Lưu ${ }^{3}$ \\ 1 Truờng Đại học Mỏ - Địa chất, Hà Nội, Việt Nam \\ ${ }^{2}$ Trường Đại học Địa chất Thăm dò mang tên Sergo Ordzhonikidze, Moscow, Liên bang Nga \\ 3 Tổng cục Địa chất và Khoáng sản Việt Nam, Hà Nội, Việt Nam
}

\begin{tabular}{|c|c|}
\hline THÔNG TIN BÀI BÁO & TÓM TẮT \\
\hline $\begin{array}{l}\text { Quá trình: } \\
\text { Nhận bài 11/5/2021 } \\
\text { Sưa xong 16/8/2021 } \\
\text { Chap nhận đăng 15/9/2021 } \\
\text { Tù khóa: } \\
\text { COSCAD-3D, } \\
\text { Dị thường trọng lực } \\
\text { Bughe, } \\
\text { Lọc hai chiều, } \\
\text { Phương pháp đa dấu } \\
\text { hiệu, } \\
\text { Xác suất thống kê. }\end{array}$ & 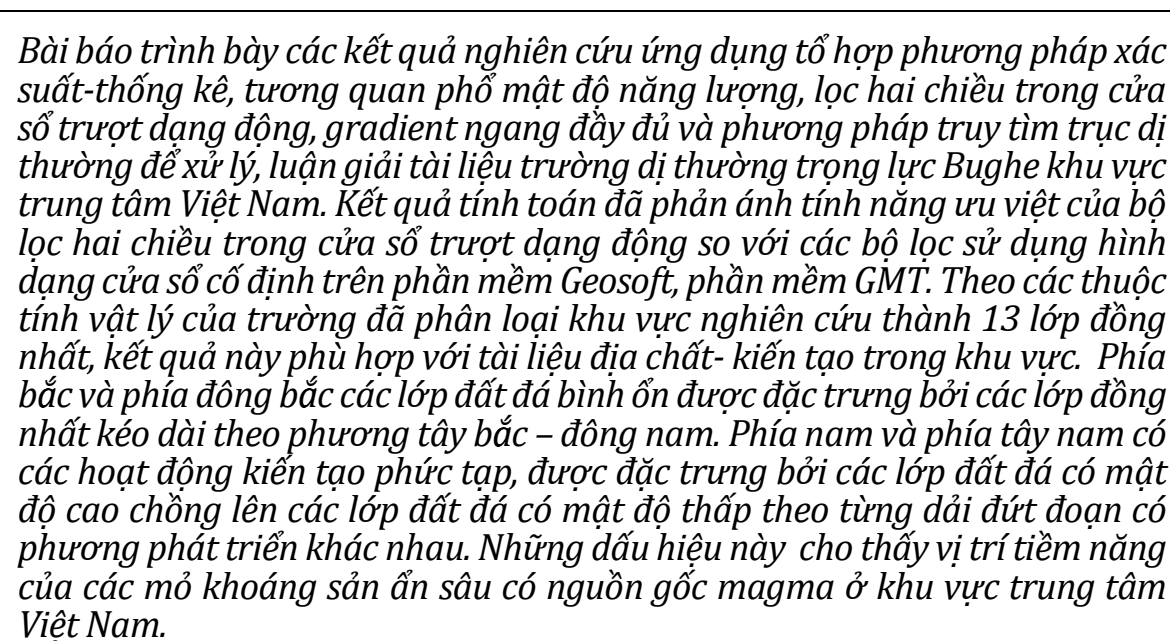 \\
\hline
\end{tabular}

C 2021 Trường Đại học Mỏ - Địa chất. Tất cả các quyền được bảo đảm.

\section{Mở đầu}

Khu vực miền Trung Việt Nam là nơi phát triển và giao nhau của các khối cấu trúc lớn như đai uốn nếp Trường Sơn, đới khâu Tam Kì - Phước Sơn, khối nâng Kon Tum,... mà ranh giới của các cấu trúc này là các đứt gãy sâu theo phương tây bắc - đông nam, đông bắc - tây nam và á kinh tuyến (Trần Văn Trị và Nguyễn Xuân Bao, 2008; Hai Thanh Tran và nnk., 2014; Quyen và nnk., 2019) (Hình 1a). Đồng thời trong khu vực có địa hình phức tạp với nhiều dãy núi cao với độ cao

\section{${ }^{*}$ Tác giả liên hệ}

E - mail: phanthihong@humg.edu.vn

DOI: 10.46326/JMES.2021.62(5).04 

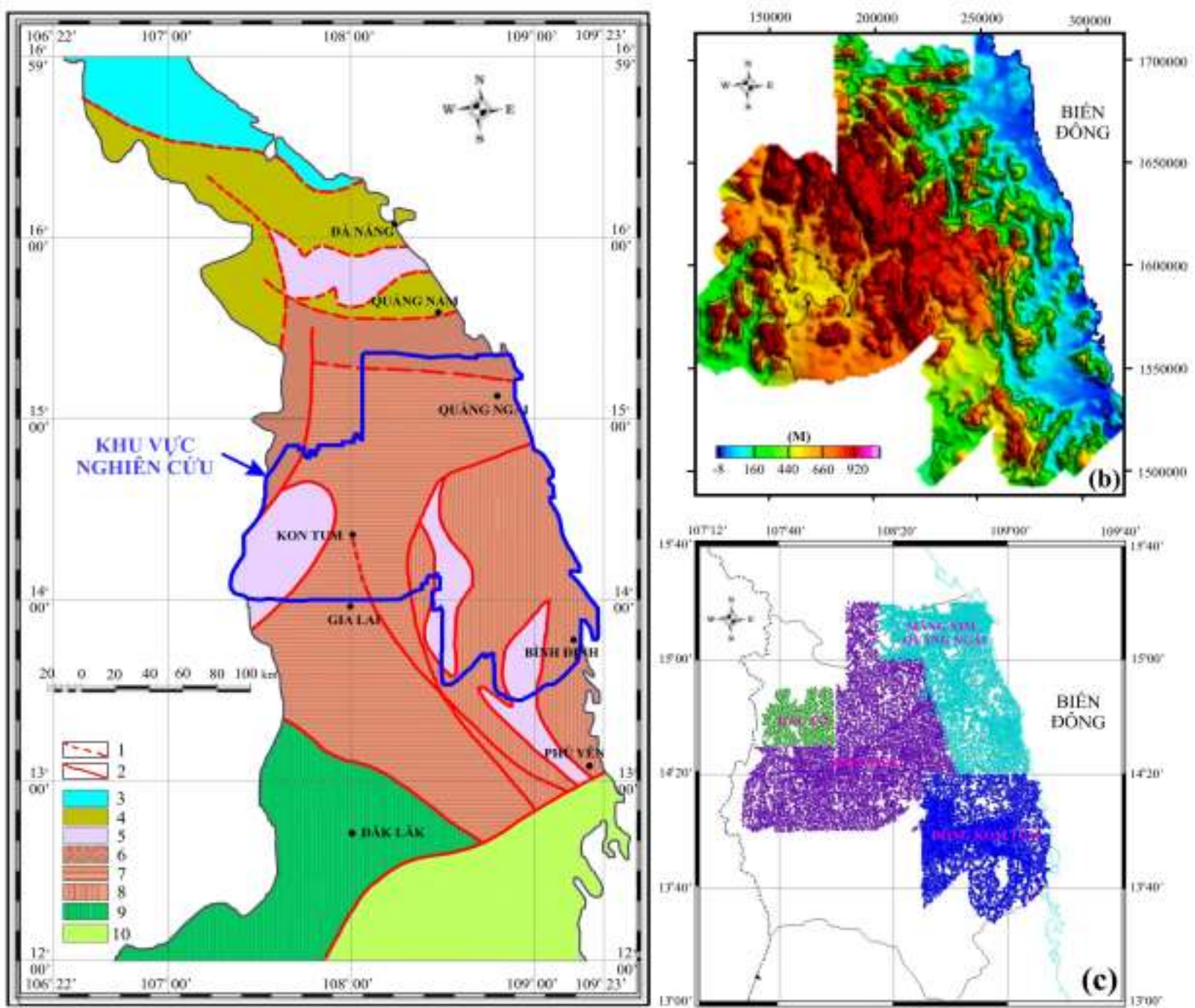

\section{Ghi chú:}

(a)

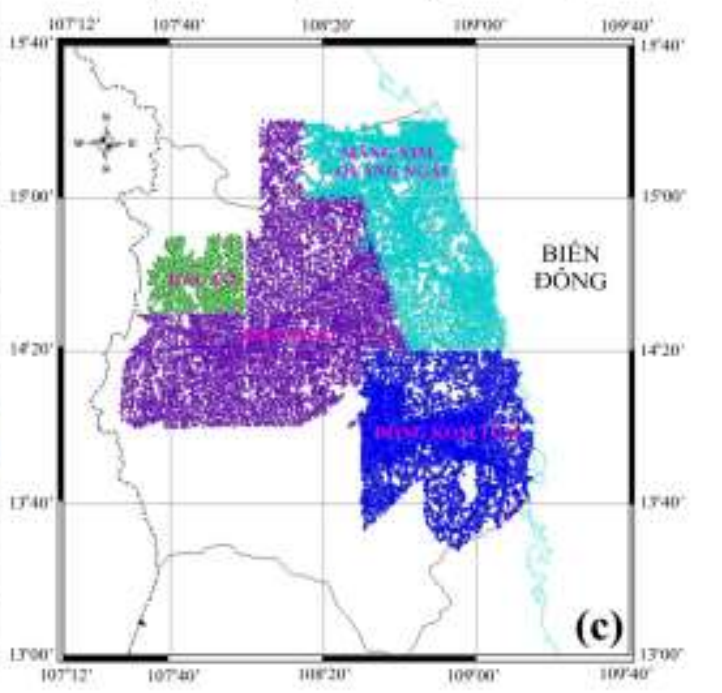

1. Hệ thống đứt gãy kiến tạo đự kiến; 2. Hệ thống đứt gãy kiến tạo; 5. Hệ rift nội lục sau va chạm Mesozoi;

3. Đai tạo núi Paleozoi muộn - Mesozoi sóm Trường Sơn;

6. Á lục địa khu Nam Ngãi; 7. A lục địa khu Ngọc Linh;

4. Đai tạo núi Paleozoi giữa Đà Nẵng - Sê Kồng;

9. Đai tạo núi Indosini MeKong (Srepok-Tây Nam Bồ);

8. Á lục địa khu Kan Nack;

10. Ria lục địa tích cực Mesozoi muộn Đà Lạt ;

Hình 1: (a) - Bản đồ cấu trúc địa chất khu vực miền Trung Việt Nam (Tran Van Tri and Nguyen Xuan

Bao, 2008) và vị trí khu vực nghiên cứu; (b)-So đồ độ cao địa hình so với mực nước biển tỷ lẹ 1:200.000 với độ cao thay đổi tù -10m đến 1.100 m (https://topex.ucsd.edu); (C) - Diện tích đo ghi trường dị thường trọng lực mặt đất tỷ lệ 1:100.000 khu vực nghiên cúu (Nguyễn Trương Lưu, 2000; 2014; Nguyễn Xuân Sơn , 2000).

>700 m (https://topex.ucsd.edu) (Hình 1b) kéo dài theo phương đông bắc, tây bắc, kinh tuyến tạo thành các thung lũng hẹp và phân cách hiểm trở, chúng tạo nên địa hình phân cắt mạnh với các hệ thống phá hủy kiến tạo ở trên mặt và dưới sâu. Đây là những điều kiện thuận lợi để hình thành các mỏ khoáng sản nội sinh có nguồn gốc magma và việc khoanh định các cấu trúc địa chất liên quan đến vị trí các mỏ khoáng sản nội sinh là nhiệm vụ quan trọng và ưu tiên trong những năm tới. Hơn nữa, tất cả các thông tin này đều được đặc trưng bởi các giá trị mật độ dư khác nhau, và được thể hiện trên các giá trị trường dị thường trọng lực đo trên bề mặt quan sát (Hình 6a). 
Giá trị trường dị thường trọng lực đo trên mặt là giá trị chồng chập của nhiều đối tượng địa chất nằm gần nhau gây ra, kết hợp với cấu trúc địa chất dưới sâu chúng ta cần tìm không biết trước và chúng thay đổi mang tính ngẫu nhiên, chính những nguyên nhân này làm cho trường dị thường trọng lực do các đối tượng có mật độ cao gây ra thường phức tạp và khó khăn trong quá trình luận giải.

Hơn nữa, các kết quả phân tích tài liệu trọng lực ngày nay chủ yếu để giải quyết các vấn đề cấu trúc như: xác định vị trí hệ thống đứt gãy, xác định độ sâu các ranh giới cấu trúc sâu (mặt Moho, mặt Conrat, mặt móng trầm tích), hoặc là giải ngược dị thường trọng lực dưới dạng tuyến sau đó liên kết với địa chất (Nguyễn Trương Lưu, 2000, 2014; Nguyễn Xuân Sơn, 2000; Nguyễn Như Trung và nnk., 2018). Thêm nữa, các kết quả phân loại địa chất theo diện tích thường dựa vào tổ hợp các phương pháp địa chất và ở Việt Nam chưa có công trình nào sử dụng đơn thuần tài liệu trọng lực và các phép biến đổi tài liệu trọng lực để phân loại thành các lớp đồng nhất theo giá trị trường và đồng nhất theo các tham số vật lý để luận giải địa chất, cung cấp thông tin đầy đủ và chính xác cho các nhà địa chất và nhà địa vật lý có các quyết định xử lý ở các công đoạn tiếp theo.

Để giải quyết tối ưu nhiệm vụ trên, nghiên cứu này sử dụng tổ hợp phương pháp xác suất thống kê, tương quan phổ mật độ năng lượng, lọc hai chiều trong cửa sổ trượt dạng động, gradient đầy đủ trường dị thường, và các kết quả trên được sử dụng làm thông số đầu vào của phương pháp phân loại quan sát đa chiều kết hợp với việc sử dụng phần mềm công nghệ "COSCAD-3D" để xử lý, phân tích và luận giải tài liệu trường dị thường trọng lực khu vực nghiên cứu (Petrov và nnk., 2010; Nikitin và Petrov, 2017; Nikiti và nnk., 2017; Petrov, 2018; Nikitin và Ivanov, 2018).

\section{Nguồn số liệu và phương pháp nghiên cứu}

\subsection{Nguồn số liệu sử dụng}

Nguồn số liệu sử dụng trong bài báo là nguồn số liệu trường dị thường trọng lực Bughe tỷ lệ 1:100.000 đo trên mặt đất sau khi hiệu chỉnh độ cao, hiệu chỉnh lớp giữa với mật độ $\delta_{\mathrm{lg}}=2.67 \mathrm{~g} / \mathrm{cm}^{3}$ và hiệu chỉnh địa hình theo phương pháp Prisivanco. L. N (Blakely, 1996). Nguồn số liệu được tổng hợp từ 4 khu vực đo độc lập: khu vực
Măng Xim, Đắc Tô, Kom Tum và Đông Kon Tum (Hình 1c), phủ đều trên diện tích đo ghi 19.730 $\mathrm{km}^{2}$ với độ chính xác $0,1 \div 0,25 \mathrm{mGal}$ (Nguyen Trương Luu, 2000; 2014; Nguyen Xuan Son và nnk., 2000). Với nguồn số liệu này, các tác giả mới dừng lại ở quá trình xử lý độc lập để xác định vị trí hệ thống đứt gãy, xác định độ sâu mặt móng cấu trúc mà chưa xử lý tổ hợp các thuộc tính của trường dị thường trọng lực để phân vùng lãnh thổ thành các lớp đồng nhất theo giá trị trường và đồng nhất theo các thuộc tính tham số vật lý.

Quan sát bản đồ trường dị thường trọng lực Bughe trên Hình 6a nhận thấy, trường dị thường trọng lực thay đổi trong khoảng từ $-100 \div 35$ mGal và trường có xu hướng tăng dần theo phương tây bắc - đông nam đi ra phía biển. Điều này cho thấy bức tranh trường dị thường trọng lực có mối tương quan ngược với địa hình bề mặt, dị thường trọng lực âm mạnh tương ứng với địa hình cao và ngược lại (Hình 1b).

Phía tây bắc trường dị thường trọng lực thấp nhất trong khu vực với giá trị âm lớn thay đổi từ -

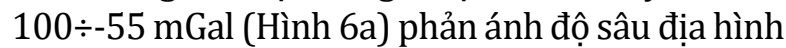
bề mặt Moho sâu nhất trong khu vực. Phía đông và đông nam giá trị trường dị thường thay đổi từ $-30 \div 35 \mathrm{mGal}$ và có hướng đường đẳng trị chạy dọc theo phương tây bắc-đông nam, phản ánh mặt Moho khu vực này được nâng cao nhất trong khu vực (Nguyen Nhu Trung và nnk., 2018).

\subsection{Phưong pháp nghiên cúru}

Quá trình phân vùng khu vực nghiên cứu thành các lớp đồng nhất theo tham số địa chất, địa vật lý nhất định và các thuộc tính của chúng là nhiệm vụ quan trọng và thiết yếu trong lĩnh vực địa vật lý ứng dụng. Ngày nay, các kết quả phân vùng thường dựa theo hai thuộc tính: giá trị trường dị thường trọng lực và trường dị thường từ, và kết quả phân vùng chỉ dựa trên tính logic và trực giác của người phân tích mà chưa xét đến các phép biến đổi làm nổi bật thông tin dẫn đến kết quả phân loại chưa chính xác và thiếu thông tin. Để tăng độ tin cậy của kết quả phân vùng lãnh thổ, phương pháp phân loại quan sát đa chiều được sử dụng dựa trên kết quả phân tích tổ hợp thuộc tính của trường gồm: đặc trưng xác xuất thống kê, tương quan phổ của trường, kết quả lọc trường, kết quả tính giá trị gradient, kết quả truy tìm trục dị thường và các thông tin địa chất có trong vùng. Kết quả đã phân vùng lãnh thổ thành những vùng 
đồng nhất dựa trên một tập hợp (cụm) các đặc trưng giống nhau. (Nikitin và Petrov., 2017; Petrov và nnk., 2010; http://www.coscad3d.ru).

\subsubsection{Phương pháp lọc hai chiều trong cưa sổ trượt dạng động}

Giá trị trường quan sát trên bề mặt là giá trị trường tổng của nhiễu và tín hiệu có ích (gồm các đối tượng địa chất địa phương và các đối tượng địa chất khu vực), mỗi đối tượng này đều được đặc trưng bởi một dải phổ năng lượng khác nhau. Vì vậy để quan sát rõ thông tin trường của các đối tượng địa chất khác nhau chúng tôi sử dụng phương pháp lọc hai chiều trong cửa trượt dạng động để phân tách.

Thuật toán lọc hai chiều trong cửa sổ trượt dạng động xây dựng dựa trên quá trình thích ứng với những thay đổi về đặc tính tương quan thống kê và phổ của trường và được tích hợp trên phần mềm công nghệ COSCAD-3D (Petrov và nnk., 2010; Nikitin và Petrov., 2017; Petrov, 2018, http://www.coscad3d.ru). Khi đó hình dạng và kích thước cửa sổ lọc được thay đổi liên tục để thích ứng với những thay đổi đặc tính tương quan phổ của trường quan sát.

Cơ sở lựa chọn kích thước cửa sổ lọc (gồm: chiều rộng, chiều cao, độ dốc và trọng số) dựa trên phân tích hàm tương quan hai chiều (DAKP, TDAKP), được tính giữa các điểm đo dọc theo tuyến và giữa các tuyến đo với nhau. Bán kính tương quan được tính theo công thức:

$$
R(p, m)=\frac{1}{N-|p|} \frac{1}{n-|m|} \sum_{k=1}^{N-|p|} \sum_{i=1}^{n-|m|} \Delta g_{k}\left(x_{i}\right) \Delta g_{k+p}\left(x_{i+m}\right)
$$

Trong đó: $\Delta \mathrm{gk}(\mathrm{xi})$ - giá trị trường dị thường trung tâm trên tuyến khảo sát $\mathrm{k}$ ở điểm thứ $\mathrm{i} ; \mathrm{p}$ độ lệch giữa các tuyến khảo sát: $\mathrm{p}=0 ; \pm \Delta \mathrm{y} ; \pm 2 \Delta \mathrm{y}$; ....; $\mathrm{m}$ - độ lệch giữa các điểm đo dọc theo tuyến khảo sát: $\mathrm{m}=0 ; \pm \Delta \mathrm{x} ; \pm 2 \Delta \mathrm{x} ;$....; $\mathrm{N}$ - tổng số tuyến khảo sát; $\mathrm{n}$ - tổng số điểm đo dọc theo tuyến khảo sát.

Thuật toán của bộ lọc hai chiều trong cửa sổ trượt dạng động được thực hiện theo quy trình trên Hình 2.

Ở Việt Nam, phần lớn các nhà xử lý thường sử dụng các bộ lọc tích hợp trên các phần mềm Geosoft, GMT (Geosoft, 2008; GMT, 2006), các bộ lọc này chủ yếu sử dụng các bộ lọc với kích thước cửa sổ cố định di chuyển trên toàn bộ diện khảo sát với quá trình lựa chọn tham số kích thước cửa sổ (chiều rộng, chiều cao, độ dốc và trọng số) chủ yếu theo ý kiến chủ quan của người phân tích, điều này dẫn đến kết quả lọc sẽ làm mất hoặc méo các thông tin có ích có liên quan đến đối tượng nghiên cứu.

Để thấy được đặc điểm ưu việt của bộ lọc hai chiều trong cửa sổ trượt dạng động so với bộ lọc

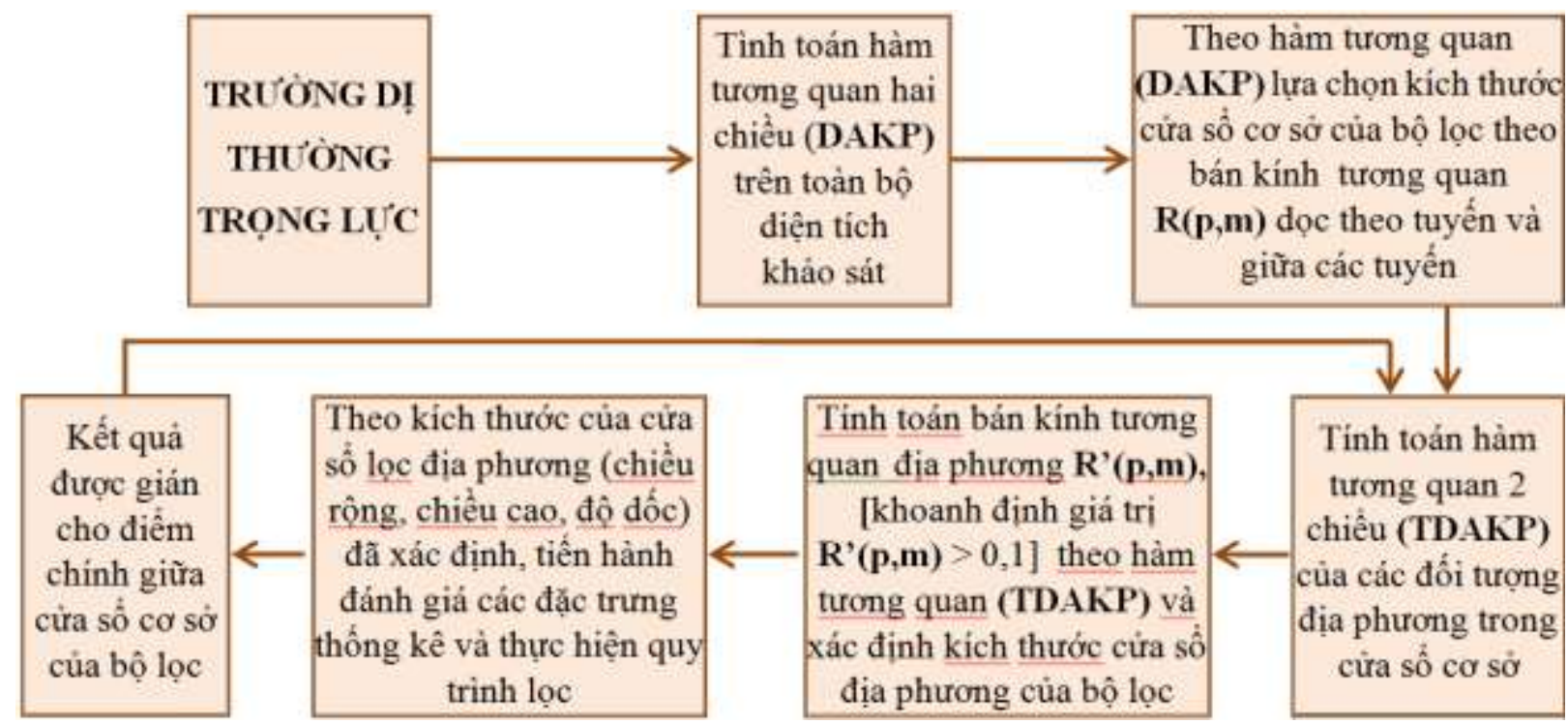

Hình 2. Sơ đồ thuật toán của bộ lọc hai chiều trong cưa sổ trượt dạng động để phân tách trường dị thường trọng lực thành các trường thành phần khác nhau. 
tích hợp trên phần mềm Geosoft, GMT (Geosoft, 2008; GMT, 2006). Nghiên cứu đã khảo sát các bộ lọc trên mô hình lý thuyết, mô hình lý thuyết được xây dựng trên phần mềm MATLAB bao gồm 2 đối tượng (khối chữ L, hình cầu) với tham số và hình dạng đối tượng thể hiện trên Hình 3 và sau đó thêm nhiễu ngẫu nhiên được kết quả thể hiện trên Hình 4.

Quan sát trên Hình 4(C), do sự cản trở của thành phần nhiễu ngẫu nhiên, chúng ta rất khó quan sát thấy hình dạng trường dị thường của khối chữ $L$ và quả cầu tạo ra. Để thấy rõ hai khối dị thường (khối chữ L và quả cầu) nghiên cứu thực hiện phương pháp lọc năng lượng với các thuật toán lọc tích hợp trên các phần mềm Geosoft, GMT (Geosoft, 2008; GMT, 2006) và thuật toán lọc hai chiều trong cửa sổ trượt dạng động, kết quả lọc được thể hiện trên Hình 5.

Kết quả lọc với kích thước cửa sổ cố định (Hình $5 \mathrm{a}$ ) và kết quả lọc trên phần mềm Geosof (Hình $5 b$ ) tạo hiệu ứng gộp giữa hai đối tượng (khối chữ L và quả cầu) do quá trình lọc chỉ sử dụng một hình dạng cửa sổ với kích thước cố định di chuyển trên toàn bộ diện tích khảo sát mà không xét đến đặc tính tương quan của trường. Kết quả lọc đã làm mất và méo thông tin trường, làm cho người xử lý tài liệu có những quyết định sai lệch trong quá trình luận giải và phân tích. Ngược lại, kết quả lọc sử dụng bộ lọc hai chiều trong cửa sổ trượt dạng động (Hình $5 c$ ) đã phân tách trường thành hai khối dị thường độc lập (khối chữ L và quả cầu) có hình dạng hoàn toàn khớp với hình dạng mô hình trường dị thường Hình 4A khi không có nhiễu ngẫu nhiên. Kết quả lọc tối ưu do trong quá trình lọc hình dạng cửa sổ lọc luôn thay đổi để thích ứng với những thay đổi về đặc tính tương quan thống kê và phổ của trường, cụ thể thuật toán đã phân tách phổ của trường dị thường của hai đối tượng (khối chữ $L$ và quả cầu) và phổ của trường nhiễu ngẫu nhiên, sau đó thực hiện quá trình lọc thích ứng phù hợp.

\begin{tabular}{|c|c|c|c|c|c|c|c|c|c|}
\hline \multicolumn{7}{|c|}{ Kỉch thước mó hình khố chữ $\mathrm{L}$} & \multirow{2}{*}{$\begin{array}{l}\text { Kich } \\
\text { thước } \\
\text { quà cầu }\end{array}$} & \multirow{7}{*}{ 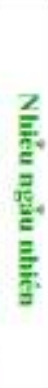 } & \multirow{7}{*}{${ }^{5}$} \\
\hline Đièm & 1 & 2 & 3 & 4 & 5 & 6 & & & \\
\hline Tọ độ: $\mathrm{x}, \mathrm{m}$ & $x_{1}=200$ & $x_{2}=800$ & $x_{3}=800$ & $x_{4}=350$ & $x_{5}-350$ & $x_{6}=200$ & $\mathrm{x}_{0}=570$ & & \\
\hline Tọa độ: y, m & $\mathrm{y}_{1}=200$ & $y_{2}=200$ & $y_{3}=400$ & $\mathrm{y}_{4}=400$ & $y_{5}=800$ & $y_{6}=800$ & $y_{0}=620$ & & \\
\hline Độ sâu: $\mathrm{H}_{1}$ m & \multicolumn{3}{|c|}{$\mathrm{H}_{1}=50$} & \multicolumn{3}{|c|}{$\mathrm{H}_{2}=200$} & $\mathrm{H}_{0}=150$ & & \\
\hline $\begin{array}{l}\text { Māt đọ đư: } \\
\Delta \sigma, \mathrm{kg} / \mathrm{m}^{3}\end{array}$ & \multicolumn{6}{|c|}{$\Delta \sigma=500$} & $\Delta \sigma=300$ & & \\
\hline Bản kỉnh: $\mathrm{R}, \mathrm{m}$ & & & & & & & $\mathrm{R}_{0}=200$ & & \\
\hline
\end{tabular}

Hình 3. Tham số và hình dạng mô hình khối chũ L và hình cầu.

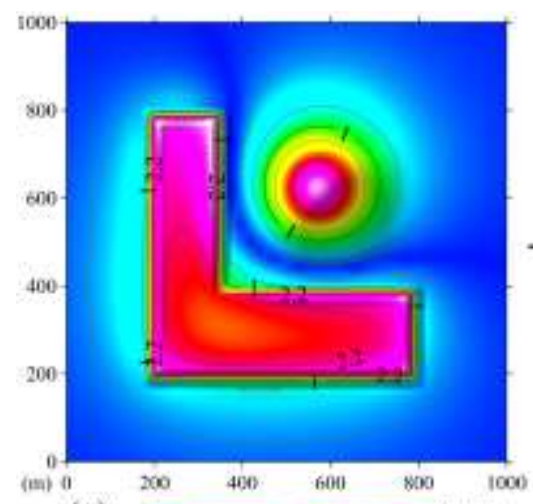

(a)

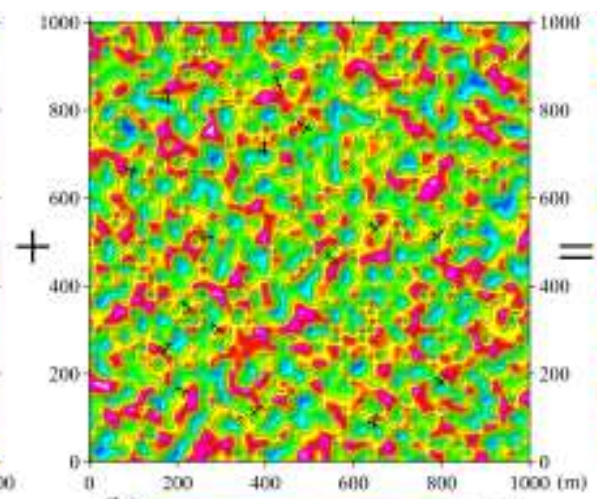

(b)

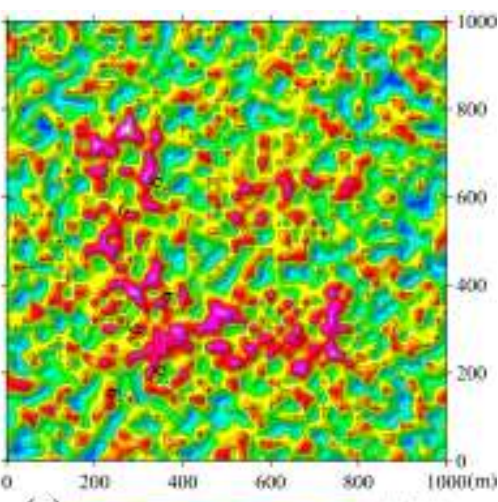

(c)

-10 $0.5 \quad$ i $15 \quad 2 \quad 2.5$

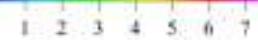

Hình 4. Kết quả trường dị thường của mô hình xây dựng trên phần mềm MATLAB: (a) - trường dị thường trọng lực của khối chứ L và quả cầu, (b) - trường nhiễu ngẫu nhiên, (c)- trường dị thường tổng của khối chũ L, quả cầu và nhiễu ngẫu nhiên. 


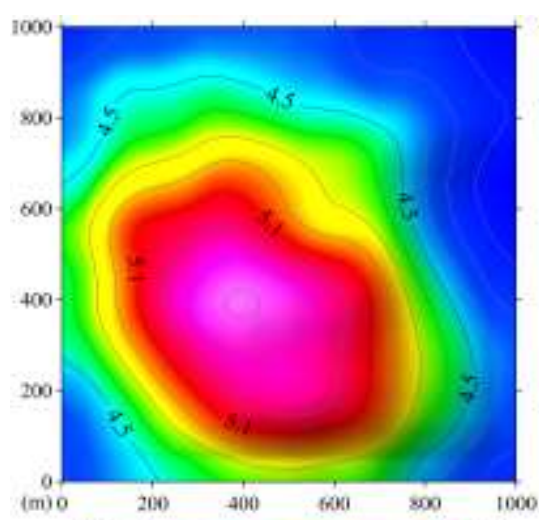

(a)

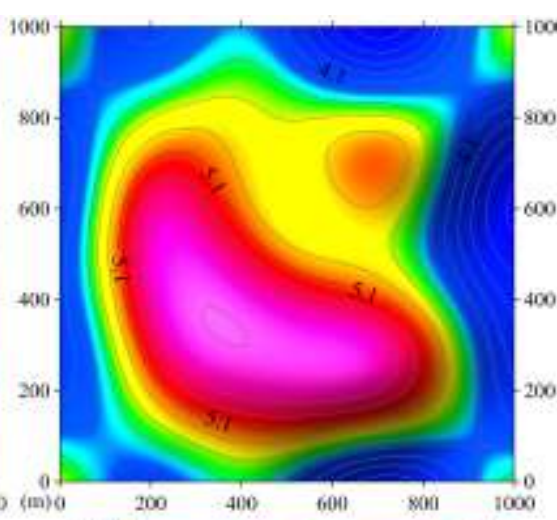

(b)

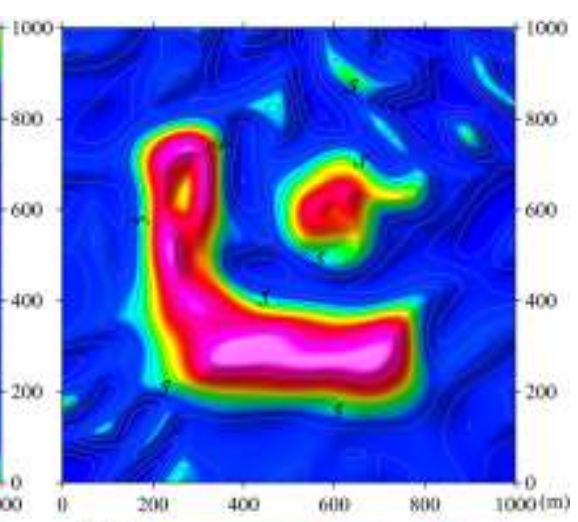

(c)

$\begin{array}{lllllll}3.2 & 3.7 & 4.2 & 4.7 & 5.2 & 5.7\end{array}$

Hình 5. Kết quả lọc trường dị thường tổng (gồm khối chữ L, quả cầu và nhiếu ngẫu nhiên) hình 4c: (a)- kết quả lọc sử dụng kích thước cửa sổ cố định 390×390 m; (b)- kết quả lọc của bộ lọc tích hợp trên phần mềm Geosoft với kích thước cửa sổ 390×390 m; (c)- kết quả lọc sử dụng bộ lọc hai chiều trong cứa sổ trượt dạng động với kích thước cứa sổ 390×390 m.

Từ kết quả phân tích mô hình trên chúng ta thấy với bộ lọc hai chiều trong cửa sổ trượt dạng động có nhiều ưu điểm nổi bật so với các bộ lọc sử dụng cửa sổ cố định, và bộ lọc tích hợp trên phần mềm Geosoft, GMT. Bộ lọc đã xem xét tối đa tính không ổn định của các trường địa vật lý và loại trừ các tác động tiêu cực trong quá trình lọc mà không thích ứng. Khi đó, thông tin của bộ lọc sẽ được tối ưu hóa theo hình dạng dị thường và không làm mất các thông tin có ích trong quá trình lọc.

\subsubsection{Phương pháp tính giá trị gradient đầy đủ trường dị thường trọng lực}

Giá trị gradient đầy đủ trường dị thường trọng lực cho phép chúng ta chi tiết hóa các đặc trưng của trường và nhấn mạnh vị trí của các ranh giới đối tượng dị thường. Phân tích các đặc trưng gradient của các quan sát địa chất - địa vật lý theo diện tích, được tính dọc theo tuyến: $\Delta g_{x}=\partial \Delta g / \partial x$, tính vuông góc với tuyến $\Delta g_{y}=\partial \Delta g / \partial y$ và giá trị gradient đầy đủ theo diện tích: $\Delta g_{x y}=\sqrt{(\partial \Delta g / \partial x)^{2}+(\partial \Delta g / \partial y)^{2}}$. (Petrov A. V. và nnk., 2010; Nikitin A. A. and Petrov A. V., 2017; http://www.coscad3d.ru).

Phân tích các đặc tính gradient của trường dị thường trọng lực cho phép:

- Nhấn mạnh ranh giới của các đối tượng dị thường, được đánh dấu bằng các điểm cực trị trong trường gradient dọc theo các trục và cực đại trong trường gradient đầy đủ;
- Làm nổi bật ranh giới của các dị thường ở các biên độ khác nhau, cho cái nhìn trực quan đồng thời các đường bao của tất cả các dị thường trên diện tích khảo sát;

- Các đặc trưng gradient dọc theo một hướng nhất định làm nhấn mạnh ranh giới của các dị thường và hướng tấn công của chúng vuông góc với hướng này.

\subsubsection{Phương pháp xử lý tổ hợp các số liệu địa vật lý}

Đối với các kết quả phân vùng chỉ dựa theo thuộc tính giá trị trường dị thường trọng lực thì kết quả phân vùng chỉ dựa trên tính logic và trực giác của người phân tích mà chưa xét đến các thuộc tính biến đổi làm nổi bật thông tin của trường, dẫn đến kết quả phân vùng chưa chính xác và thiếu thông tin. Để tăng độ tin cậy của kết quả phân vùng lãnh thổ, phương pháp phân loại quan sát đa chiều được sử dụng: phương pháp dựa trên kết quả phân tích tổ hợp thuộc tính của trường (gồm: đặc trưng xác xuất thống kê, tương quan phổ của trường, kết quả lọc trường, kết quả tính giá trị gradient ngang đầy đủ và các thông tin địa chất có trong vùng), kết quả phân vùng lãnh thổ thành những vùng đồng nhất dựa trên một tập hợp (cụm) các đặc trưng giống nhau. (Petrov A. V. và nnk., 2010; Nikitin A. A. and Petrov A. V., 2017; http://www.coscad3d.ru).

Thuật toán cho phép phân loại các quan sát địa vật lý đa chiều thành các vùng đồng nhất (các vùng có cùng giá trị vectơ trung bình trên toàn bộ 
thông tin tín hiệu). Thuật toán được xây dựng dựa trên cơ sở kiểm tra giả thuyết thống kê đa chiều và được phân tách thành hai bước chính:

Bước 1: Giả thuyết được kiểm tra về sự liên kết giữa hai vùng khác nhau thành một lớp. Ban đầu giả định số vùng bằng số điểm quan sát, có nghĩa là mỗi điểm thuộc một lớp. Trong trường hợp này, nếu hai lớp kiểm tra thỏa mãn giả thuyết ở mức nhất định thì chúng sẽ kết hợp với nhau thành một lớp. Số lượng lớp ban đầu được giảm đi một và ước lượng ma trận phương sai $S$ được tính toán lại, ma trận là giá trị quan trọng để tính toán thống kê các tiêu chí tương ứng với giả thuyết. Bước 1 kết thúc khi giả thuyết về sự kết hợp các lớp không thỏa mãn.

Bước 2: Phân loại dữ liệu được chia thành các lớp ở kết quả 1 . Sau đó bước đầu tiên được lặp lại, đồng thời lúc bắt đầu thống kê, tiêu chí kiểm tra giả thuyết kết hợp hai lớp khác nhau được sử dụng để ước tính ma trận phương sai $\mathrm{S}$ và được nhận trong bước đầu tiên của quá trình xử lý.

Để thực hiện quy trình trên cần phải sử dụng các tiêu chí thống kê đa chiều để kiểm tra các giả thuyết trên.

\section{Nội dung và kết quả đạt được}

\subsection{Kết quả phân tách trường thành phần trong khu vực nghiên cứu}

Theo sơ đồ thuật toán của bộ lọc hai chiều trong cửa sổ trượt dạng động (Hình 2), thuật toán của bộ lọc dựa trên quá trình phân tích đặc tính tương quan phổ của trường và mỗi dải đối tượng sẽ được đặc trưng một dải phổ khác nhau và dựa trên cơ sở đó nghiên cứu này đã loại bỏ thành phần nhiễu ra khỏi trường dị thường tổng thành 3 thành phần (mỗi thành phần đặc trưng cho một dải phổ nhất định): thành phần trường dị thường khu vực (Hình 6b), thành phần trường dị thường địa phương cục bộ bậc 1 (Hình $6 \mathrm{c}$ ) và thành phần trường dị thường địa phương cục bộ bậc 2 (Hình 6d).

Quan sát Hình 6b thấy trường dị thường khu vực thay đổi từ $-75 \div 10$ mGal với xu hướng trường tăng dần theo phương tây bắc - đông nam, có tương quan ngược với địa hình khu vực, đồi núi cao ở phía tây bắc và thấp ở phía đông nam (Hình 1b), phản ánh địa hình mặt Moho thấp ở phía tây bắc và cao ở phía đông nam.
Quan sát Hình 6c và 6d nhận thấy, trong khu vực tồn tại khá nhiều các khối bất đồng nhất địa phương phân bố với mật độ khá dày trong khu vực. Cụ thể, trên Hình $6 \mathrm{c}$ biên độ dao động từ $-10 \div 12,5 \mathrm{mGal}$, các bất đồng nhất mật độ dư dương tập chung chủ yếu ở phía bắc, trung tâm và phía tây nam khu vực với biên độ dao động từ $8 \div 12,5$ mGal. Trên Hình $6 \mathrm{~d}$ phản ánh các khối bất đồng nhất địa phương có kích thước nhỏ gần bề mặt với biên độ dao động từ $-4,5 \div 6,0 \mathrm{mGal}$, các khối bất đồng nhất địa phương có mật độ dương tập trung chủ yếu ở phía bắc, trung tâm và phía tây khu vực nghiên cứu.

\subsection{Kết quả phân tích giá trị gradient đầy đủ trường dị thường trọng lực khu vực nghiên cứu}

Để có cái nhìn trực quan ranh giới đường bao của các khối bất đồng nhất địa phương và ranh giới các hệ thống đứt gãy trong khu vực nghiên cứu, nhóm nghiên cứu tính giá trị gradient đầy đủ trường dị thường Bughe tổng (Hình 6a), tính giá trị gradient đầy đủ trường dị thường khu vực (Hình 6b) và nhận được kết quả lần lượt trên Hình $7 \mathrm{a}$ và Hình $7 \mathrm{~b}$.

Quan sát Hình 7a thấy các dải giá trị gradient đầy đủ kéo dài theo nhiều phương khác nhau với biên độ thay đổi từ $0,0005 \div 0,0065 \mathrm{mGal} / \mathrm{m}$. Nổi bật, ở trung tâm khu vực quan sát dải giá trị cực đại gradient dạng khối với biên độ lớn hơn 0,005 $\mathrm{mGal} / \mathrm{m}$ phản ánh có thể đây là khối magma khá lớn trong khu vực. Ở phía tây bắc khu vực quan sát thấy các dải cực đại gradient kéo dài liên tục dạng dải hoặc dạng khối với biên độ lớn hơn 0,05 $\mathrm{mGal} / \mathrm{m}$ phản ánh các ranh giới đứt gãy hoặc các khối bất đồng nhất địa phương trong khu vực.

Quan sát Hình $7 \mathrm{~b}$ thấy giá trị gradient thay đổi trong khoảng 0,0002 $\div 0,0012 \mathrm{mGal} / \mathrm{m}$, các dải giá trị cực đại gradient kéo dài chủ yếu theo phương tây bắc - đông nam, đông bắc - tây nam. Phía tây nam và phía nam khu vực quan sát thấy các dải giá trị cực đại gradient kéo dài, đứt đoạn, chồng chéo lên nhau. 

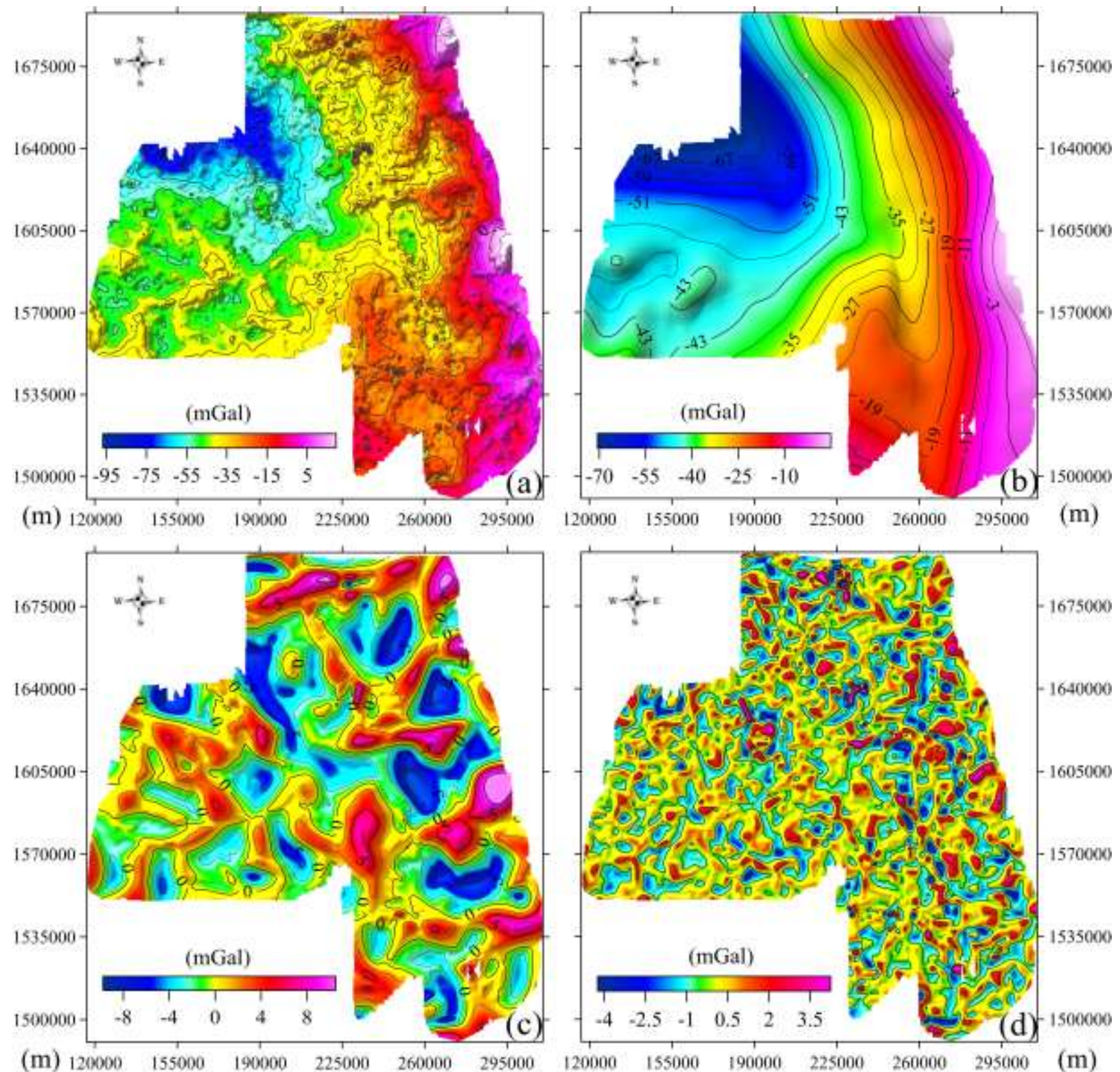

(m) $120000 \quad 155000 \quad 190000 \quad 225000 \quad 260000 \quad 295000$

$120000 \quad 155000 \quad 190000 \quad 225000 \quad 260000 \quad 295000 \quad(\mathrm{~m})$

Hình 6. Kết quả phân tách trường dị thường trọng lực Bughe khu vực trung tâm Việt Nam theo bộ lọc hai chiều trong cửa sổ trượt dạng động: (a)- trương dị thường trọng lực Bughe tỷ lệ 1:100000 (Nguyễn Truơng Lưu và nnk., 2000; 2014; Nguyen Xuan Son và nnk., 2000); (b)- thành phần trường dị thường trọng lực khu vực; (c)- thành phần trường dị thường trọng lực địa phương bậc 1 và (d)- thành phần trường dị thường trọng lực địa phương bậc 2 .

\subsection{Kết quả phân vùng lãnh thổ khu vụ̂c nghiên cúru}

Kết quả phân vùng lãnh thổ thành các vùng đồng nhất dựa trên thuật toán giả thuyết thống kê đa chiều của phương pháp phân loại địa chất theo giá trị vectơ trung bình của Петров $\mathrm{A}$. B. (Petrov A. V. và nnk., 2010; Nikitin A. A. and Petrov A. V., 2017; http://www.coscad3d.ru).
Kết quả phân vùng lãnh thổ khu vực nghiên cứu thành 9 lớp đồng nhất (Hình 8a) theo phân tích tổ hợp tài liệu trường dị thường trọng lực khu vực (hình 6b), thuộc tính gradient (Hình 7b) và các thuộc tính thống kê tương ứng. Khi phân tích thêm kết quả truy tìm trục dị thường thành phấn trường khu vực nhận được kết quả phân vùng lãnh thổ thành 13 lớp đồng nhất (Hình 8b). Kết quả phân vùng lãnh thổ trên Hình $8 \mathrm{~b}$ khá tương 


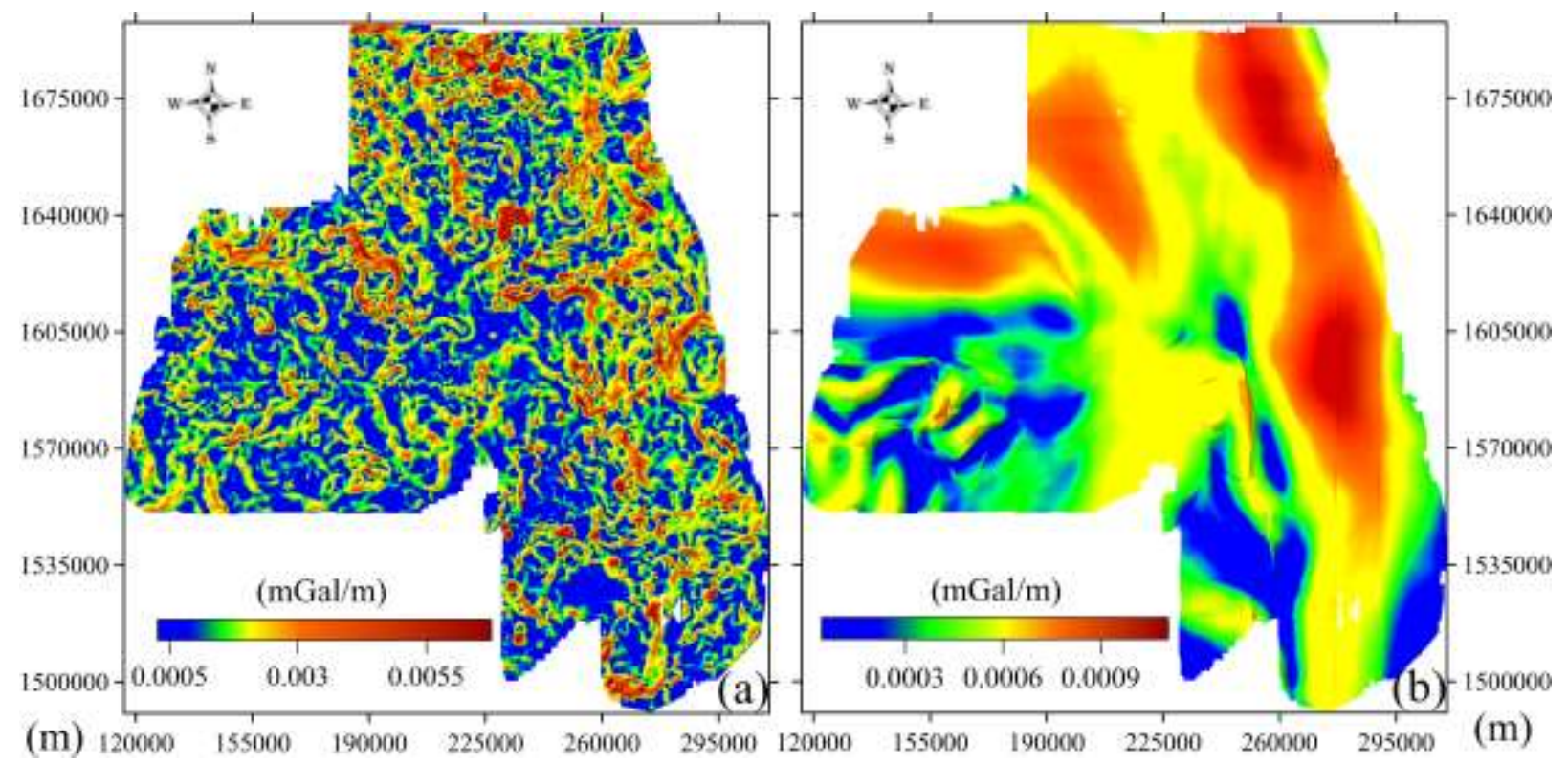

Hình 7. Kết quả tính toán giá trị gradient đầy đủ trường dị thường trọng lực khu vực trung tâm Việt Nam: (a) - Giá trị gradient đầy đủ trường dị thường trọng lực Bughe Hình 6a và (b) - Giá trị gradient đầy đủ trường dị thưòng khu vực Hình 66.
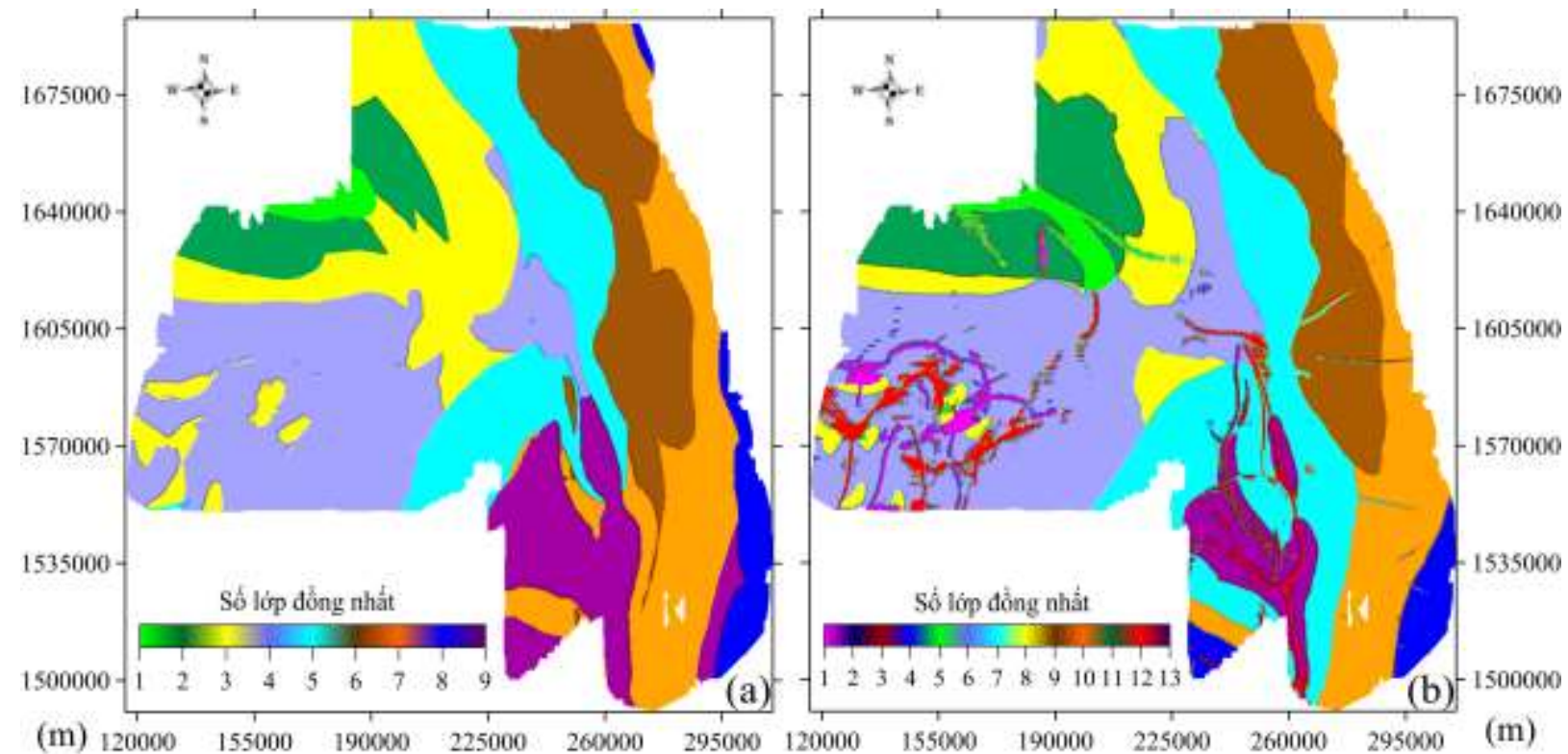

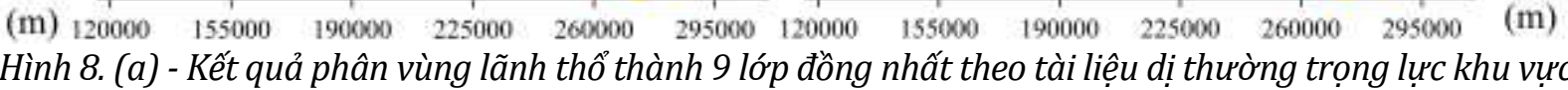
(Hình 6b) và thuộc tính gradient tương úng của trường; (b)- kết quả phân vùng lãnh thổ thành 13 lớp theo tài liệu dị thường trọng lực khu vực (Hình 6b), thuộc tính gradient và thuộc tính truy tìm trục dị thường tương úng của trường khu vực trung tâm Việt Nam.

đồng với đặc điểm địa chất kiến tạo thể hiện trên Hình $1 \mathrm{a}$.

Quan sát trên Hình $8 \mathrm{a}$, thấy phía tây nam và phía nam khu vực nghiên cứu đặc trưng bởi các loại đất đá có mật độ cao chồng lên các đá có mật độ thấp và vò nhàu, đứt đoạn theo nhiều hướng khác nhau, phản ánh khu vực có hoạt động kiến tạo phức tạp, các khối nâng lên và hạ xuống nhiều cung bậc khác nhau. So sánh với bản đồ cấu trúc địa chất khu vực miền Trung Việt Nam trên Hình 1a (Trần Văn Trị và Nguyễn Xuân Bao, 2008) thì khu vực này thuộc hệ rift nội lục sau va chạm Mesozoi và theo Hai Thanh Tran và nnk., (2014) thì hệ rift nội lục sau va chạm Mesozoi là hậu quả 
của quá trình căng giãn hậu và va chạm giữa mảng Đông Dương và Sibumasu, quá trình hội nhập và ghép nối các địa mảng dẫn tới sự xếp chồng và xuyên xắt nhau hết sức phức tạp của nhiều tổ hợp trầm tích và magma có tuổi và nguồn gốc khác nhau, và quá trình biến dạng nhiều lần dẫn tới sự phá hủy hoặc đảo lộn dạng nằm và quan hệ địa chất nguyên thủy, biến vị không gian và thành phần của các thành tạo địa chất đặc biệt thành tạo trước Mesozoi. Như vậy, kết quả phân vùng khu vực thành các lớp đồng nhất theo đồng nhất theo giá trị trường và đồng nhất theo các tham số vật lý, đặc biệt các lớp ở phía tây nam và phía nam khu vực hoàn toàn trùng khớp với tài liệu địa chất kiến tạo (Trần Văn Trị và Nguyễn Xuân Bao, 2008; Hai Thanh Tran và nnk., 2014)

Các lớp đồng nhất theo giá trị trường và đồng nhất theo các thuộc tính vật lý tương ứng nằm ở phía bắc, phía đông bắc khu vực nghiên cứu khá ổn định, mang đặc tính khu vực và kéo dài theo phương tây bắc - đông nam là do khu vực này giáp với biển Đông, vì vậy kết quả này hoàn toàn phù hợp với quy luật địa chất.

Quan sát trên Hình 8a thấy hoạt động kiến tạo vò nhàu vẫn còn tồn tại ở phía tây nam và phía nam khu vực nghiên cứu, điều này chứng tỏ các hoạt động kiến tạo này mang tính khu vực và chúng có vai trò làm kênh di chuyển các khối magma từ dưới sâu đi lên và xâm nhập vào các lớp trầm tích gần bề mặt và thành tạo các mỏ khoảng sản ẩn sâu.

Kết quả phân loại thành các lớp đồng nhất theo đặc trưng của trường phản ánh sự đồng nhất thành phần hạch học của các lớp đất đá, là tiền đề làm tăng độ tin cậy cho các quyết định của các nhà địa chất về các đặc trưng cấu trúc địa chất, có cái nhìn trực quan về quá trình hoạt động kiến tạo trong khu vực nghiên cứu.

\section{Kết luận}

Kết quả xử lý và luận giải tài liệu dị thường trọng lực Bughe khu vực trung tâm Việt Nam đưa ra một số kết luận:

- Thuật toán lọc sử dụng cửa sổ trượt dạng động ưu việt hơn so với các thuật toán lọc sử dụng cửa sổ cố định (GMT, Geosoft). Kết quả lọc đã phân chia trường dị thường trọng lực Bughe thành 3 thành phần: thành phần khu vực, thành phần địa phương bậc 1 và thành phần địa phương bậc 2 .
- Phân vùng địa chất khu vực nghiên cứu thành 13 lớp đồng nhất theo giá trị trường và đồng nhất theo tham số vật lý của trường, kết quả phân vùng này hoàn toàn trùng khớp với địa chất kiến tạo trong khu vực. Phương pháp đa dấu hiệu là phương pháp hiệu quả và tối ưu, nên áp dụng để xử lý tài liệu trường thế ở Việt Nam.

- Hoạt động kiến tạo khu vực phía tây nam và phía nam khá phức tạp với các lớp đất đá bị vò nhàu và đứt đoạn theo nhiều hướng khác nhau và đây là vị trí tiềm năng hình thành các mỏ khoáng sản nội sinh có nguồn gốc magma. Khu vực phía bắc và phía đông bắc các lớp đất đá khá bình ổn với các lớp đất đá đồng nhất kéo dài theo phương tây bắc - đông nam.

- Các kết quả phân tích và luận giải trường dị thường trọng lực bước đầu làm tăng độ tin cậy cho các quyết định của các nhà địa chất về luận giải cấu trúc địa chất và đánh giá nguồn gốc thành tạo các mỏ khoáng sản ẩn sâu trong khu vực.

\section{Lời cảm ơn}

Nhóm tác giả gửi lời cảm ơn tới Liên đoàn Vật lý địa chất, Tổng cục Địa chất và Khoáng sản Việt Nam hỗ trợ nguồn số liệu dị thường trọng lực mặt đất tỷ lệ 1:100.000. Cảm ơn GS. TSKH Petrov Aleksey Vladimirovich, Trường Địa chất Thăm dò Quốc gia Nga (MGRI) cung cấp phần mềm thương mại “COSCAD-3D” xử lý nguồn số liệu.

\section{Đóng góp của tác giả}

Phan Thị Hồng: lên ý tưởng, xử lý số liệu và hoàn thiện bài báo; Petrov Aleksey Vladimirovich: hỗ trợ phần mềm và chuyên gia cố vấn các kết quả xử lý; Đỗ Minh Phương, Nguyễn Trường Lưu: tham gia xử lý và cố vấn kiến thức địa chất - địa vật lý trong khu vực nghiên cứu.

\section{Tài liệu tham khảo}

Blakely, R. J. (1996). Potential theory in gravity and magnetic application. Cambridge University Press, 197 pages.

Geosoft. (2008). Ver. 7.01: Manuals, Tutorials, and Technical Notes. Geosoft inc.

Hai Thanh Tran, Khin Zaw, Jacqueline A. Halpin, Takayuki Manaka, Sebastien Meffre, Chun-Kit Lai, Youjin Lee, Hai Van Le, Sang Dinh. (2014). The Tam Ky-Phuoc Son shear zone in central Vietnam: 
Tectonic and metallogrnic implications. Gondwana Research 26, 144-164. https://topex.ucsd.edu/cgi-bin/get_data.cgi. http://www.coscad3d.ru/index.php. http://www.agu.org/eos_elec/95154e.html http://www.geosoft.com

Nikitin D.S., Gorskikh P.P., Khutorkoy M.D, Ivanov D.A., (2017). Phân tích và mô hình số các dòng tiềm năng ở phía đông bắc của biển Barents, Nga. Khoa học trái đất, UDK 550.361, 1(30), 6-15.

Nikitin. D. S., Ivanov D. A. (2018). Sự phân vùng tổ hợp cấu truc-kiến tạo khu vực đông bắc của thềm biển Barents, Nga. Georesources, UDK 550.8, 4, 404 - 412. Nikitin A. A., Petrov A.V.

(2017). Cơ sở lý thuyết về xử lý thông tin địa vật lý. Tái bản lần thứ 4. Nhà xuất bản khoa học và kĩ thuật. Matxcova, Nga, 127 trang.

Nguyễn Trường Lưu. (2000). Bay đo từ phổ gamma tỷ lệ $1: 50.000$ và đo trọng lực tỷ lệ 1 : 100.000 khu vực miền Trung Việt Nam. Trung tâm thông tin, luu trũ địa chất, Hà Nội.

Nguyễn Trường Lưu, (2014). Bay đo từ phổ gamma tỷ lệ 1:50.000 và đo vẽ trọng lực tỷ lệ 1:100.000 vùng Nam Pleiku. Trung tâm thông tin, luu trũ địa chất, Hà Nội.

Nguyễn Xuân Son, (2000). Kết quả bay đo từ phổ gamma tỷ lệ $1: 50.000$ và đo vùng Kon Tum. Trung tâm thông tin, lưu trũ địa chất, Hà Nội.
Nguyen Nhu Trung, Phan Thị Hong, Bui Van Nam, Nguyen Thi Thu Huong, Tran Trong Lap, (2018). Moho depth of the northerm Vietnam and Gulf of Tonkin from 3D inverse interpretation of gravity anomaly data. Journal of geophysics and Engineering, 1651-1662.

Petrov A.V., Yudin D.B., Soeli Hou. (2010). Xử lý và giải thích dữ liệu địa vật lý bằng phương pháp tiếp cận xác suất-thống kê sử dụng công nghệ máy tính "KOSKAD 3D". Khoa học trái đất. UDK 551-214, 2, 126-132.

Petrov A.V. (2018). Các quy trình thích ứng xử lý diễn giải các trường địa lý không cố định trong công nghệ máy túnh "KOSKAD-3D". Hội nghị khoa học quốc tế, 01-02 tháng 4, MGRI-RGRU, Moscow, Nga, 418-420.

Quyen Minh Nguyen, Quinglai Feng, Jian-Wei Zi, Tianyu Zhao, Hai Thanh Tran, Thanh Xuan Ngo, Dung My Tran, Hung Quoc Nguyen, (2019). Cambrian intra-oceanic arc trondhjemite and tonalite in the Tam Ky - Phuoc Son Suture zone, central Vietnam: Implications for the early Paleozoic assembly of the Indochina block. Gondwanna Research, 70, 151-170.

Trần Văn Trị, Nguyễn Xuân Bao. (2008). Bản đồ cấu trúc địa chất tỷ lệ 1:500.000 khu vực miền Trung Việt Nam. Trung tâm thông tin, lưu trữ địa chất, Hà Nội. 